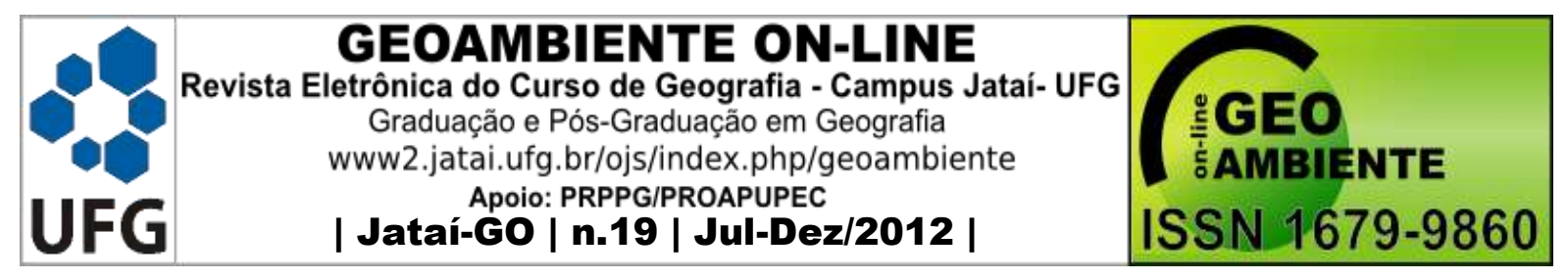

\title{
REGIÃO E REGIONALIZAÇÃO: ANÁLISE CRÍTICA DAS METODOLOGIAS APLICADAS NA FORMULAÇÃO DA POLÍTICA NACIONAL DE DESENVOLVIMENTO REGIONAL (PNRD) DO GOVERNO LULA DA SILVA NO BRASIL
}

Fabiano de Oliveira Bringel ${ }^{1}$

(1 - Universidade Federal de Pernambuco. Programa de Pós-Graduação em Geografia, Doutorando. Fabiano.bringel@ufpe.br)

\section{Resumo}

A região como conceito-chave na geografia vem sendo estudada ao longo de sua trajetória como ciência. Suas concepções e métodos subjacentes sempre se apresentaram diversos e controversos. Geralmente, na literatura geográfica, observamos um levantamento das concepções de região nas diversas escolas geográficas e seus diferentes métodos de regionalização balizados pelo contexto histórico que estão inseridas. Neste artigo, foram realizadas, abordagens pontuais sobre a definição de região e regionalização, a partir de uma introdução sobre região e positivismo, centrando a análise na abordagem sistêmica na Nova Geografia.

Palavras-chave: Região, Regionalização, Política Nacional de Desenvolvimento Regional PNDR, Governos Lula da Silva.

\section{Abstract \\ REGION AND REGIONALIZATION: REVIEW OF THE METHODOLOGIES USED \\ IN THE FORMULATION OF NATIONAL POLICY FOR REGIONAL DEVELOPMENT (PNDR) OF THE GOVERNMENT OF LULA DA SILVA IN} BRAZIL

The region is as a key concept in geography throughout its path as science. Its underlying concepts and methods are diverse and always controversial. Generally, in the geographical region in the various schools and its different methods of regionalization, marked out by the historical context which they are inserted. In this article, specific approaches were carried on

\footnotetext{
Artigo recebido para publicação em 22 de Dezembro de 2011 Artigo aprovado para publicação em 04 de Dezembro de 2012
} 


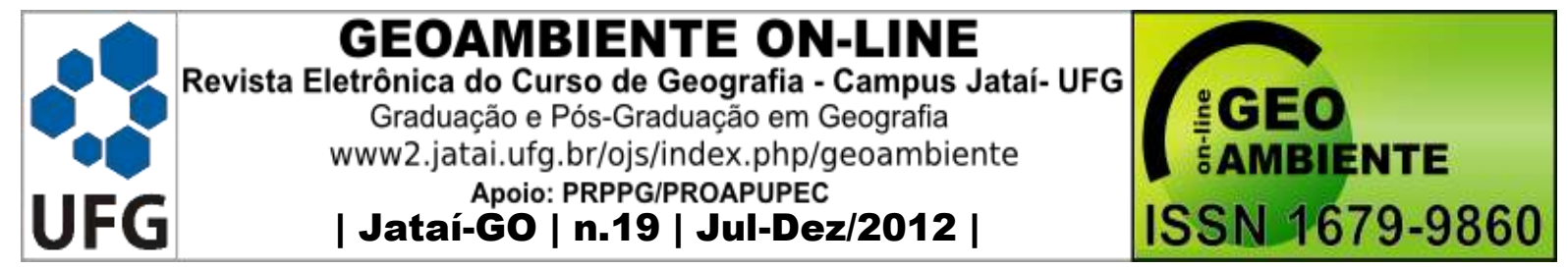

the definition of the region and regionalization, making a introductory study about region and positivism, focusing on the systemic approach in New Geography.

Key words: Region, Regionalization, National Policy for Regional Development ADRP, governments Lula da Silva.

\section{Resumen}

REGIÓN Y REGIONALIZACIÓN: ANÁLISIS CRÍTICA DE LAS METODOLOGÍAS APLICADAS EN LA FORMULACIÓN DE LA POLÍTICA NACIONAL DE DESARROLLO REGIONAL (PNRD) DEL GOBIERNO DE LULA DA SILVA EN

\section{BRASIL}

La región como un concepto clave en la geografia ha sido estudiada a lo largo de su carrera como una ciência. Sus conceptos y métodos siempre han sido diversas y controvertidas. En general, em la literatura geográfica, um estudio de las concepciones de región geográfica en las diferentes escuelas y sus diferentes métodos de regionalización marcada por el contexto histórico que insertan. En este artículo, se llevaron a cabo enfoques pontuales de la definición de región y la regionalización, haciendo una rápida introducción sobre región y positivismo, centrando en el análisis del enfoque sistémico en la nueva geografía.

Palabras Clave: Región, Regionalización, Política Nacional de Desarrollo Regional, Gobiernos Lula da Silva.

\section{A região e o positivismo - uma longa relação}

A região sempre foi concebida para fins de ação e controle (CORRÊA, 1995). Todo processo de diferenciação de área ao longo da história da humanidade é permeada de relações de poder. Divide-se ou se agrupa o espaço para melhor controlá-lo, para melhor regê-lo. Desde as primeiras regionalizações ocidentais, feitas pelo Império Romano, depois de sua primeira experiência censitária, se praticou políticas populacionais, de atração ou de repulsão, com base na leitura de regiões e sua nova política de organização regional.

Cientificamente a região começa a ser tratada a partir do século XVIII, como uma necessidade imposta pelas novas relações de produção que o novo estágio do capitalismo prescindia. A conformação do positivismo como paradigma filosófico e o liberalismo como elemento econômico necessitavam de esforços para se conhecer melhor as diferentes áreas 


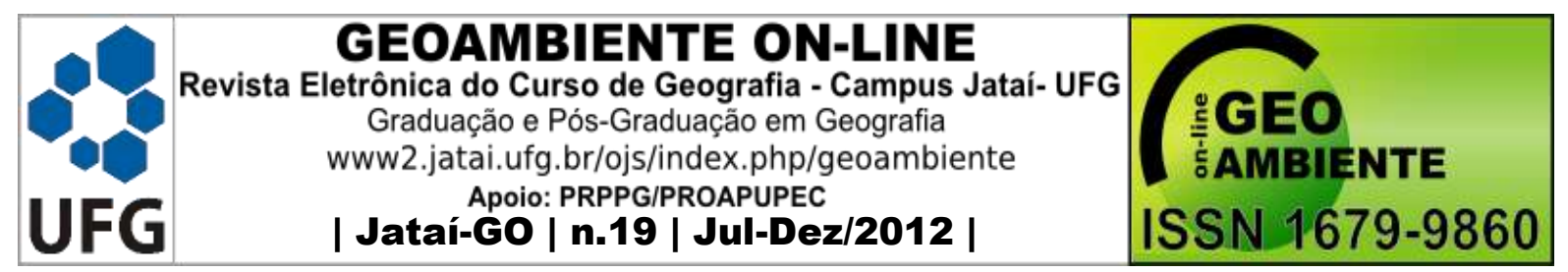

que compõe a superfície terrestre. A biologia, a física e a matemática impunham-se como ciências estratégicas e seus métodos imprescindíveis para o entendimento do real. Logo, a Geografia começa a entender as regiões como partes de um todo orgânico. Chega-se a primeira concepção científica de região na geografia: a região natural (BEZZI, 2004).

A região natural é a região do determinismo ambiental. Produto do século XIX, seu principal precursor foi Frederick Ratzel. Suas principais referências vêm de um tripé do conhecimento biológico: Lamarck (1744-1829); Darwin (1809-1882) e Spencer (1820-1903). Nesta base, Ratzel relacionava seus conhecimentos geográficos e políticos com o desenvolvimento das teorias evolucionistas. A partir dessa relação, Ratzel preocupado com configuração política européia e, sobretudo, com unificação Alemã, começa a desenvolver sua teoria baseada no equilíbrio entre população e recurso demonstrando que a distribuição do homem na superfície terrestre havia sido determinada pelas forças naturais. Na equação população-recurso, formula sua Doutrina do Espaço Vital definindo e relacionando as possibilidades de progresso e as demandas territoriais.

As tentativas de regionalização com bases deterministas aparecem num período, portanto, de intensa polaridade política. As áreas de domínios geopolíticos estavam sendo redefinidas. O determinismo desponta como um veículo de modelo de Estado e de estratégia territorial. Aparecem, também, neste contexto expressões como "fator geográfico" ou "condições geográficas", heranças do discurso ideológico determinista, entendidas como as variáveis desse critério de regionalização - o clima, solo, relevo, vegetação, hidrografia. Nesse contexto, constrói-se a regionalização e "surgem às regiões com características semelhantes em macro-escala, que receberam designações bem amplas, porém sem um significado especifico como região moçônica, região mediterrânea, região tropical, entre outras" (BEZZI, 2004:57).

Se contrapondo ao Determinismo, no final do século XIX, desponta uma nova corrente paradigmática na Geografia trazendo um debate sutilmente diferente sobre região e regionalização. O Possibilismo continua a discussão sobre a relação homem e meio, porém considerava este mesmo homem como um agente ativo sobre o meio. A natureza oferecia possibilidades que o homem escolheria através de sua cultura, materializados na paisagem através de seus costumes e hábitos. 


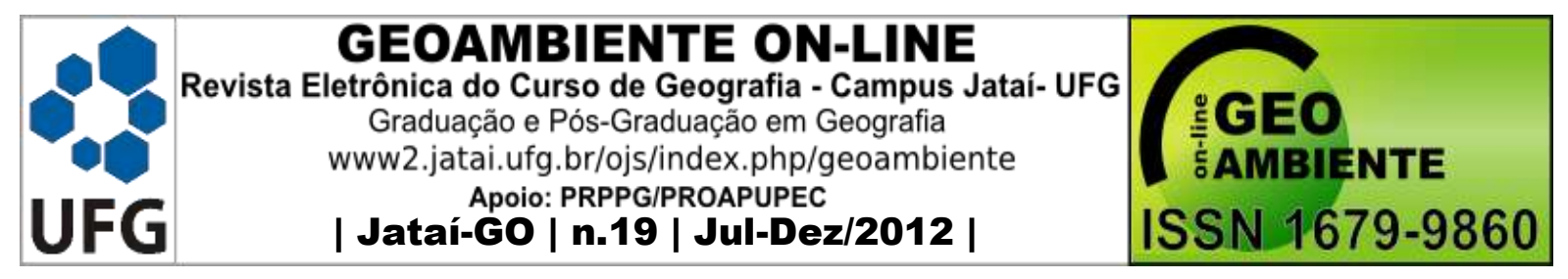

A região passou a ser resultado de uma síntese entre o homem e o meio natural. Essa síntese foi escolhida como objeto de estudo, sendo os critérios para regionalização baseados no livre arbítrio do pesquisador, levando as análises geográficas a priorizar o estudo de caso único e a consagrar a descrição regional por excelência. Seu objetivo não era estabelecer relações causais nem estabelecer leis sobre as relações homem e meio, mas observar as relações mútuas entre o homem e o ambiente, não podendo estabelecer limites entre um e outro, pois os mesmos se interpenetrariam, estando numa interface.

Para a construção de sua regionalização no Possibilismo, Vidal de La Blache desenvolveu dois grandes conceitos: modo de vida e circulação. Modo de vida era usado como referência “(...) a existência de um padrão funcional, unificado de vida, que acompanhava o comportamento etnográfico ou cultural, o componente histórico e a perspectiva ecológica da sociedade humana" (BEZZI, 2004:68). Já a circulação foi o elemento que capacitou um grupo humano a sobrepujar as condições naturais que o limitavam. Nesta perspectiva, a região seria uma progressiva comunhão entre as características sociais e as condições naturais. Seria uma entidade auto-evidente, fruto de uma larga maturação histórica.

No entanto, a região geográfica do Possibilismo se apresenta como um elemento bucólico, negligenciando a emergência de uma nova fase capitalista, onde o urbano-industrial era um elemento estratégico, como podemos observar no fragmento:

[...] arranjo particular dos elementos do quadro natural e, a seguir, sobrevinha uma visão quase bucólica da população e de suas principais atividades. Essas regiões eram produtos pictórios, fruto da limitação na observação do pesquisador interessados em gêneros de vida de aparência feudal, dentro de um modo de produção capitalista. Tal fato pode ser exemplificado pela quase inexistência de análises urbano-industriais por pesquisadores dessa corrente geográfica. (BEZZI, 2004:73)

Depois desses dois paradigmas, um terceiro se apresenta no entre guerras. Era o chamado Método Regional, que teve como protagonista Richard Hatshorne (1899-1992). Este paradigma é importante por se tratar de uma pré-geografia teorética e dar cabedal teórico e metodológico para a mesma. Para Hartshorne, a região não era auto-evidente como no Possibilismo. Seria impossível nesta perspectiva delimitar as regiões fixamente, unidades físicas concretas e individualizadas. Nesta lógica, Hartshorne, afirmava que os limites, assim 


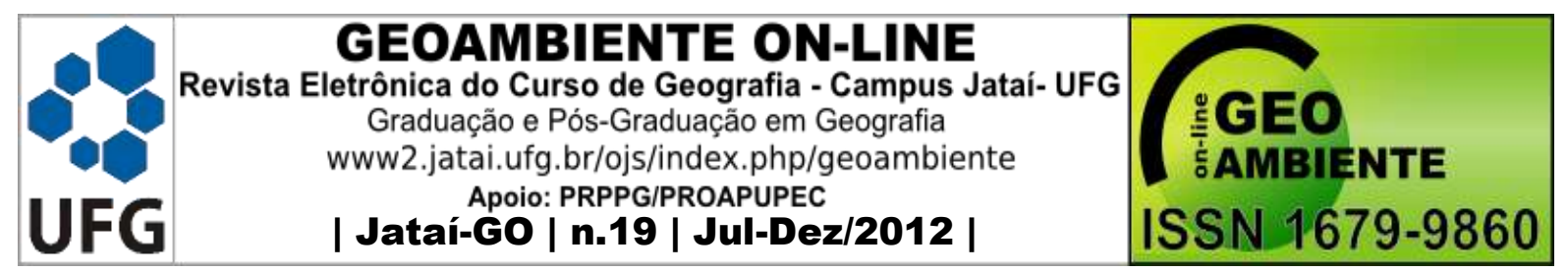

como o conteúdo regional, variavam de acordo com os propósitos do pesquisador. Não haveria um critério, mas sim um conjunto definidos arbitrariamente pelo agente regionalizador. Definiu a região em dois tipos: a homogênea e a funcional. É homogênea quando o fenômeno ou os fenômenos relacionados condicionariam a isso. Já região funcional é definida pela organização em torno de um nó comum.

\section{A Nova Geografia e sua importância para o planejamento de Estado}

No pós-guerra, o mundo observa um conjunto de mudanças no ordenamento mundial. Do ponto vista geopolítico nasce à guerra fria. Nas mudanças técnicas aparecem novos instrumentos no tratamento das informações como o computador. No campo, a chamada revolução verde se instala e, com ela, a intensificação do processo de urbanização, principalmente na periferia do modelo capitalista. Na ciência, observamos a emergência do neo-positivismo, acionando a passagem de um positivismo empírico para a um positivismo lógico. Essas mudanças afetam consideravelmente o conhecimento geográfico. Emerge, então, a Nova Geografia. Preocupada em subsidiar o Estado no desenvolvimento de pesquisas e estudos de campo, os métodos estatísticos de análise, as classificações e novas regionalizações compõem a mais nova tônica dessa nova geografia. No bojo desse movimento quantitativo, duas figuras se destacaram Fred Schaefer (1904-1953) e Willian Bunge (19281998). Dentre os seus métodos, se valoriza a construção de modelos e de teorias gerais como a Teoria Geral dos Sistemas.

Discuti-se a noção de complexos espaciais ou regionais, se preocupando com a construção de uma abordagem multidimensional. Neste sentido, compreende-se o espaço geográfico como complexo e sistêmico, onde qualquer variável espacializada tem um valor que só pode ser mensurado quando relacionado com os espaços vizinhos. Desenvolvem-se, então, com maior substância científica as noções de região polarizada, região funcional e regiões homogêneas. Todas balizadas através de um nó, um pólo, que irá influenciar e atrair um conjunto espacial.

Como métodos de construção desses modelos regionais se desenvolveram duas perspectivas: o sintético e o analítico. O sintético parte do agrupamento em classes. Para Haesbaert é "um agrupamento de partes menores em parcelas mais amplas, mas menores que o todo (por exemplo: região como agrupamento de estados brasileiros - o Sul, o Nordeste)" 


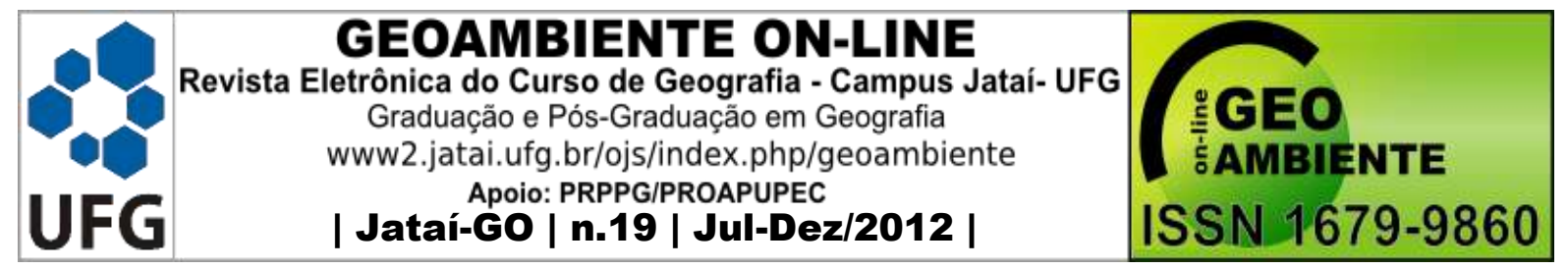

(HAESBAERT, 1992:107). O analítico divide uma área em regiões, criando uma tipologia dos fenômenos selecionados. Haesbaert definira como "uma divisão do conjunto, do todo, em partes menores (ex.: as regiões do mundo estabelecidas a partir da divisão internacional do trabalho definida pelos centros do capitalismo)" (HAESBAERT, 1992:107). Neste sentido, o método analítico estaria relacionado a uma abordagem teorético-dedutivo. O sintético relacionado a uma abordagem empírico-indutivo. Como afirma o autor no fragmento abaixo:

Priorizar o todo - o que ocorre no processo de divisão, que vai do todo às partes -
implica um método teórico-dedutivo, enquanto que priorizar a parte - no caso do
agrupamento - leva a um método empírico-indutivo. Se quisermos de fato assumir
uma perspectiva dialética de conhecimento será imprescindível reconhecer, no
mínimo, que ambos os processos são limitados e que a realidade só pode ser
entendida quando a reconhecemos numa dinâmica de mão dupla (embora desigual):
tanto do todo para a parte (ou, numa outra abordagem, do geral para o particular)
quanto da parte para o todo. Alguns racional-idealistas defenderiam a primeira
perspectiva, enaltecendo o geral, a teoria, e impondo-a sobre as especificidades,
enquanto muitos materialistas empíricos tomariam por base à segunda, priorizando a
singularidade ou as particularidades no entendimento do mundo. (HAESBAERT,
1992:107)

Nesta observação sobre a construção de métodos de regionalização mais eficazes, é preciso inferir sobre as duas formas acima levantadas sob o risco de nossas abordagens acabarem se tornando limitadas. Tanto do todo para as partes como das partes para todo, desenvolvendo uma via de mão dupla, mesmo percebendo que elas se configuram desigualmente.

Um dos instrumentos muito utilizados na construção dessa aparente abordagem de mão dupla é o sistemismo. Esta concepção se destaca em nossa pesquisa já que o elemento central desse trabalho é uma análise sobre a metodologia utilizada na construção da política regional do Governo Lula. Esta metodologia esta calcada na abordagem sistêmica. Relação esta, que iremos trabalhar mais a frente. Neste momento, apresentaremos os componentes centrais desse tipo de abordagem na análise regional.

Em primeiro lugar é preciso fazer uma correlação entre sistema e estrutura, pois "toda estrutura oferece um caráter de sistema" (LEVI-STRAUSS, 2008:301). Assim, Demo (1981) afirma que existe uma aparente coincidência entre os dois conceitos. No entanto, afirma que os conceitos se condicionam, mais é preciso que exista uma estrutura prévia e necessária para o que o sistema exista. Apesar de muito próximos, o estruturalismo e o sistemismo são diferentes. Identificamos em Demo (1981) sua principal diferença - o estruturalismo privilegia 


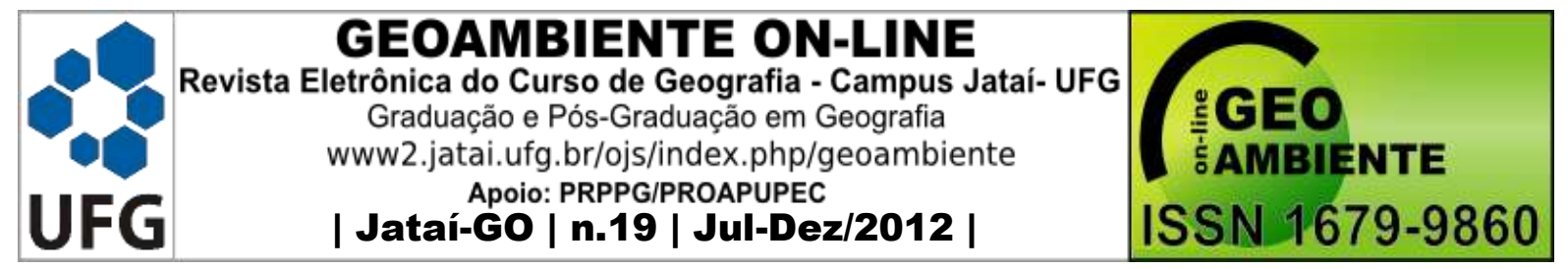

a análise, a decomposição analítica dos elementos do todo; o sistemismo privilegia de partida, a síntese, a visão da totalidade, o que lhe daria um aparente toque dialético.

A Teoria Geral dos Sistemas de Bertalanffy influenciou decisivamente a Nova Geografia. Essa Teoria, baseada na termodinâmica da física, compreende que os conjuntos de elementos em suas inter-relações definem o estado interno do sistema, seja na organização ou desorganização. É, portanto, o conjunto dos elementos e das relações entre eles. O princípio básico do estudo de sistemas em geografia é a conectividade. Esses sistemas podem ser classificados em abertos ou fechados, de acordo com as circunstâncias de troca ou não de energia com exterior. $\mathrm{O}$ estudo de região nesse debate se configuraria como um sistema aberto, em constante troca de energia com o exterior, ou seja, nas diversas inter-relações que a região mantém com espaços vizinhos ou próximos (BEZZI, 2004).

A estrutura da região na abordagem sistêmica é caracterizada pelas propriedades e pelas relações de seus elementos. Assim, as propriedades de cada lugar estão determinadas por subsistemas (estruturas locais) configuradas pelos estados e suas diversas conexões (econômica, demográfica, social, cultural, física, etc.) e pelas relações entre essas conexões. A região, ainda nesta perspectiva, pode enlaçar setores heterogêneos através de um centro, de um nó ou pólo, como podemos avaliar abaixo:

\footnotetext{
Essas relações ou fluxos correspondem a determinadas funções que o centro desempenha, especialmente funções econômicas (produção e distribuição de bens industriais, realização e distribuição de serviços, etc.). As áreas que ficam configuradas como resultado desses fluxos têm sido designadas com o nome de funcionais. Freqüentemente, esses centros correspondem a núcleos urbanos destacados, sendo por isso, denominados de áreas de influência urbana. (BEZZI, 2004:131)
}

No sistemismo podemos dizer que a região é um sistema. Neste sistema atuam inputs, que seriam os componentes que penetrariam no organismo (sistema), e os outputs, seriam os elementos que sairiam do organismo através de várias formas. O in e out se retroalimentariam através dos feedbacks.

Na literatura especializada sobre a abordagem sistêmica no processo de regionalização encontramos uma distinção entre input interno e externo: o interno origina-se no próprio sistema, o externo vem de fora. Destaca duas possibilidades de input externo - uma baseada em uma fonte permanente, regular, fornecida pelo sistema por sua situação geográfica e 


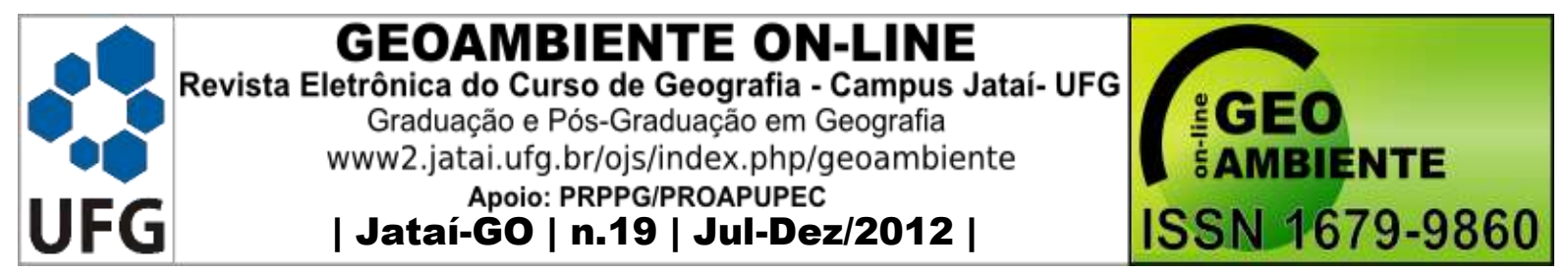

política, que se denomina input nacional; e uma segunda, consistindo de fontes irregulares, não controladas, distantes, que se denomina de input global. Assim, o input nacional é a soma de influências que afetam a região como parte de um Estado ou uma nação: intervenções por instituições nacionais ou públicas, pela legislação, pelo planejamento nacional, por projetos em desenvolvimento, por ajuda governamental; ou limitações, pelos fluxos de informação ou pelo capital sendo a região um subsistema do Estado. Como input global entende-se aquilo que não sendo de origem nacional trás influências ou alterações a região, ou seja, demandas do mercado mundial, inovações tecnológicas, culturais e científicas, investidores, troca de conhecimento na ciência e na educação, ajuda estrangeira, etc.

O input interno é composto das qualidades ambientais, demográficas, culturais, econômicas e políticas da população da região. Tais qualidades são influenciadas pelos inputs nacionais e globais.

Faremos agora um pequeno exercício sobre construção de políticas regionais para verificarmos se o estudo de região se configuraria como um sistema aberto. Partiremos da noção que a região seria permeada da relação entre demanda e suporte. As demandas seriam vinculadas à população como água, habitação, segurança, créditos e fomentos, telefonia. Essas demandas seriam os inputs que precisariam ser atendidos ou entrar no planejamento ou execução de políticas para a região. $\mathrm{O}$ suporte seria a contrapartida através do teor de legitimação dentro do sistema e que é condicionada a base da persistência. Toda essa carga entraria no sistema. As autoridades, por sua vez, planejam os outputs respondendo especificamente as pressões. Tais outputs se ligam aos inputs através do feedback, estabelecendo sua eficiência histórica e sua persistência numa perspectiva auto-reguladora.

Nesse esquema, para Marcuse \& Habermans apud Demo (1981), haveria um crescente modelo de fechamento da sociedade. A dita abertura do sistema e, em última instância, a abertura da própria região é no fundo falsa, porque serve apenas para captar as tensões sociais e elaborar para elas (no caso o Estado, sua regionalização e sua política regional) as condições necessárias para a volta ao equilíbrio anterior.

$\mathrm{Na}$ análise de Bezzi (2004) as regiões na análise sistêmica estariam classificadas em dinâmicas, estáveis ou em deterioração:

[...] existem regiões dinâmicas nas quais os processos mudam o caráter básico da região, ou seja, o caráter permanente é o mesmo em alguns aspectos, mas diferente em outros. Há regiões com certa estabilidade, onde predomina um "steady state", 


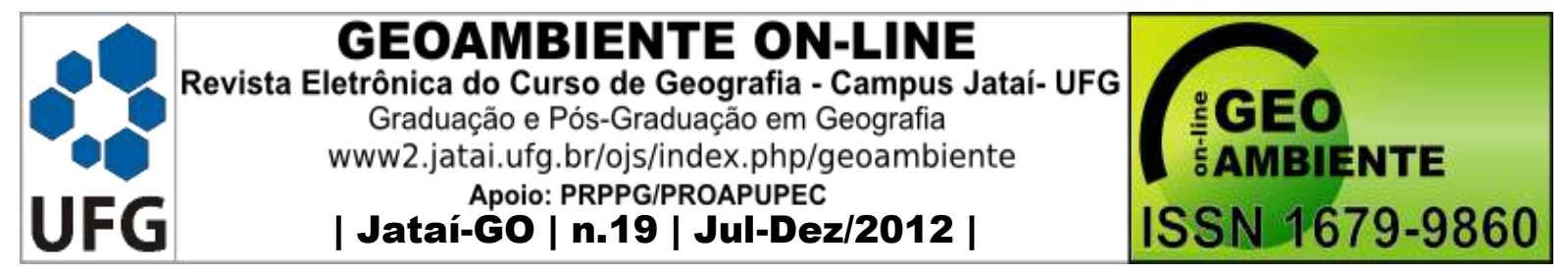

uma vez que os processos e o feedback preservam a natureza constante do output. Há também regiões onde domina a entropia, e somente processos pequenos fornecem um fluxo mínimo. E finalmente, há regiões "morrendo", onde toda atividade diminui e o processo principal é uma deteriorização da população e dos elementos da paisagem. (BEZZI, 2004:133)

Nesta mesma lógica, a Política Nacional de Desenvolvimento Regional - PNRD (BRASIL, 2009) do Governo Lula classifica suas áreas. Priorizando as microrregiões, definiuas a partir do cruzamento de duas variáveis - rendimento domiciliar e crescimento do PIB per capita.

O resultado desse cruzamento foram quatro microrregiões: a) Microrregiões de Alta Renda - encontradas quase todas nas regiões Sul, Sudeste e Centro Oeste. Apresentam um rendimento domiciliar alto e por isso não são foco de prioridade do PNDR. São responsáveis por $76 \%$ do PIB nacional e apresentam apenas 53,7\% da população; b) Microrregiões Dinâmicas - Com rendimentos médios e baixos, porém apresentam forte dinâmica econômica. Tem mais incidência no Centro Oeste e no Nordeste brasileiro; c) Microrregiões Estagnadas - apresentam rendimento domiciliar médio, mas com baixo crescimento econômico. Apresenta forte dinamismo no passado, um relativo grau de urbanização e apresentam uma relativa dispersão pelo território nacional; d) Microrregiões de Baixa Renda - são áreas com baixo rendimento domiciliar e baixo dinamismo. São concentradas no Norte e Nordeste do país. Baixo grau de urbanização participa com apenas 1,7\% do PIB embora abrigue $8,4 \%$ da população brasileira.

Ao classificar as regiões como de alta renda, dinâmicas, estagnadas e baixa renda, o Estado brasileiro, através do Governo Lula, se afilia fundamentalmente a abordagem sistêmica de regionalização. Para entendermos melhor essa nova regionalização precisamos examinar a PNRD e sua concepção de desenvolvimento.

\section{A Política Nacional de Desenvolvimento Regional - PNRD e concepções de desenvolvimento}

É fato que o fenômeno da globalização aprofundou as diferenças entre as regiões no planeta. Regiões se tornaram dinâmicas e cada vez mais ricas e outras estagnaram, ou mesmo, retrocederam, aprofundando fortemente as desigualdades espaciais. Por outro lado, a 


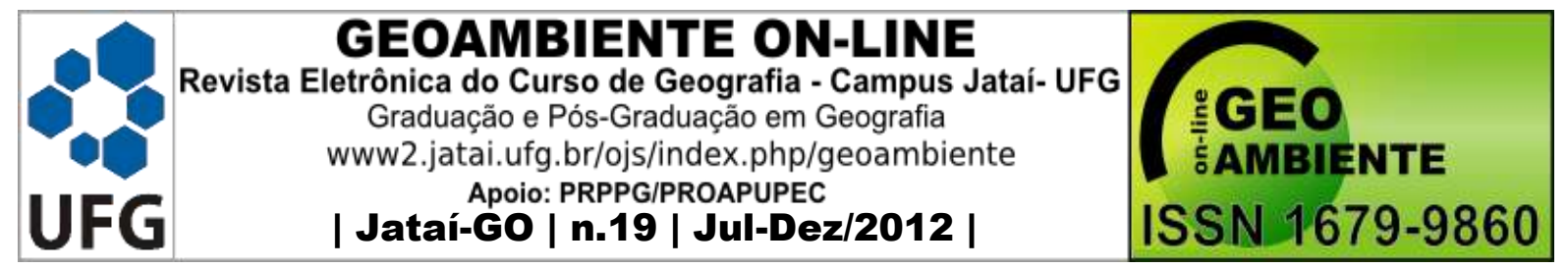

mundialização do capital solapou muitos governos nacionais e locais, fazendo que os mesmos perdessem o controle de seu "desenvolvimento".

As conseqüências desse fenômeno são desastrosas. A intensificação das migrações internacionais, problemas ambientais, a desmetropolização, êxodo rural, acirramento dos conflitos étnico-religiosos são faces dessa nova face do sistema-mundo.

Os estados nacionais preocupados com essas conseqüências começaram a adotar, no pós-guerra, um conjunto de políticas visando combater os malefícios de um mundo cada vez mais integrado. Num primeiro momento, essas políticas visavam atrair as grandes empresas, na maioria das vezes transnacionais, para as regiões menos desenvolvidas através de incentivos e isenções fiscais, créditos a baixos juros, investimentos em grandes obras logísticas. O resultado não foi o esperado. Pelo contrário, acirrou, ainda mais, as desigualdades regionais. Era visão exógena de desenvolvimento que imperava.

A partir de 1980, emerge gradativamente um novo paradigma de desenvolvimento. Com iniciativas governamentais de planejamento voltadas para a valorização do potencial endógeno do território, se toma como exemplos o Vale do Silício nos EUA, a Emília Romana na Itália, algumas regiões com dinamismo na Ásia. Essas políticas apresentam-se "ancoradas em territórios específicos; baseadas em pequenas e médias empresas, interdependentes e interativas; não se limitam às regiões caracterizadas pela produção flexível e alta tecnologia [...]" (BRASIL, 2009:09).

O que se questiona aqui é que se a matriz de pensamento sobre "desenvolvimento" não for rompida, dificilmente teremos a capacidade de andarmos com as nossas próprias "pernas". Fazemos esse questionamento sob a ótica do pós-desenvolvimento. Corrente de pensamento que vê no desenvolvimento um problema. Não no tipo de desenvolvimento, mas no próprio desenvolvimento. Autores como Deleuze, Guatarri, Focault, Homi Bhabha, Frans Fanon fazem parte dessa escola do pós-desenvolvimento. Seu objetivo consiste em

[...] desmontar esse artifício chamado desenvolvimento para mostrar uma incongruência e a necessidade de superá-lo, não reformá-lo. A desconstrução do desenvolvimento elaborada pelo pós-desenvolvimento, portanto, responde à necessidade de mostrá-lo como historicamente construído e racionalmente exótico para a maior parte da humanidade, enfim, parcial apesar de sua pretensão de universalidade. (Gómez, 2007:40) 


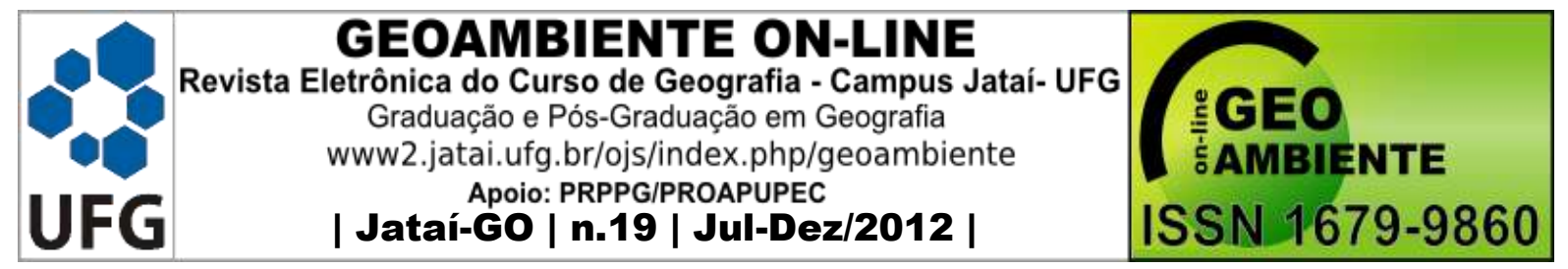

Assim, o desenvolvimento aparece como uma pretensa "religião", onde Rist (2002) questiona a partir de quatro aspectos: a) conseqüência da arrogância ocidental, que considera a sociedade moderna distinta por ser racional e secularizada, como se não tivesse suas próprias crenças e contradições; b) fundamentada em crenças formuladas de forma simples e nas quais se acredita "porque se pensa que todo mundo acredita, porque não se pode fazer outra coisa que acreditar, porque todo mundo diz a mesma coisa" (p.33) ou porque existiria alguma obscura autoridade, como os planejadores e as pesquisas de opinião; c) eficácia dessas crenças que obrigam a atuar de uma determinada forma, sem opção; d) utilização de certos rituais e signos, como fóruns, exposições, inauguração de barragens, rodadas de negociações comerciais, etc.

Para termos a clareza sobre a PNRD e como ela parte de uma concepção de desenvolvimento de matriz européia, visto como uma "religião" precisamos examinar a metodologia utilizada pelo Ministério da Integração para se chegar a PNRD.

Os dados utilizados na formulação da PNRD foram retirados do IBGE, dos censos demográficos de 1991 e 2000 e das estimativas de PIB municipais, realizados pelo IPEA Instituto Nacional de Pesquisas Econômicas Aplicadas. As variáveis contêm elementos como distribuição e características da população - rendimento médio, local de residência e nível de educação; o dinamismo econômico captado por meio da variação do PIB per capta.

Os dados foram agregados por microrregiões, escala considerada a mais adequada para os propósitos da análise. Os indicadores de dinamismo foram obtidos por média geométrica do crescimento do PIB per capta nos triênios de 1990 - 1993 e 1999-2002 de cada município e posteriormente agregados em microrregiões.

No nosso entendimento esta metodologia procura romper com a lógica das macrorregiões que foram o objeto das políticas de desenvolvimento regional nas décadas de 1960 e 1970. Essas macrorregiões, segundo Brasil - Ministério do Interior (2000), não são mais as unidades regionais representativas nem operacionais no país, afirmando que não se pode pensar sobre um espaço que não existe mais. Porém, quando a PNRD propõe a revitalização de instituições como SUDAM, SUDENE e SUDECO temos a clareza que o Ministério da Integração formula uma metodologia nova de análise regional e propõe velhas formas de operacionalizar essa política. O resultado é uma política que, no seu cerne, é contra-sensual. 


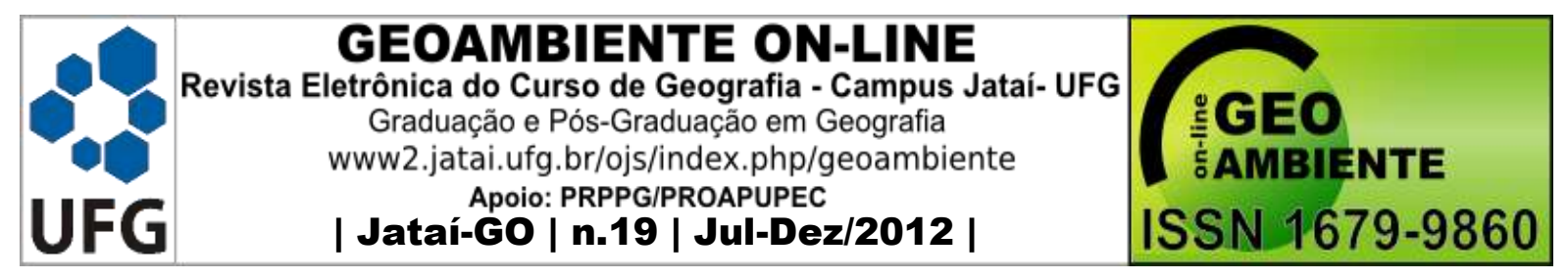

A PNDR aponta que historicamente a população brasileira está espacialmente concentrada no litoral do país e no entorno das metrópoles. A este adensamento se contrapõe espaços com densidade populacional baixa como a Amazônia, o Centro Oeste e o Semi-árido nordestino. Mas, no entanto, este mesmo documento apresenta uma tendência na última década à interiorização da população. Este mesmo documento discute duas polarizações distintas no território nacional. Uma expressa no binômio litoral-interior e outra no sentido Norte-Sul. No que se refere ao litoral-interior, as desigualdades se expressam na densidade populacional, enquanto que, na relação norte-sul, são os indicadores como nível de escolaridade, grau de urbanização e rendimento médio domiciliar que compõem a diferenciação (BRASIL, 2009).

Ao apontar essas polaridades, o documento deixar transpassar nas entrelinhas que é preciso fazer uma distribuição equânime da população pelo território nacional. Em nossa compreensão, isto se revela como um erro de análise, já que nós temos biomas sensíveis a um grau elevado de antropização como o Pantanal e a Amazônia (que corresponde a um pouco mais de $60 \%$ do território nacional).

Outro elemento afirmado constantemente no documento se refere ao grau de urbanização como um indicador de desenvolvimento. Maior grau, maior desenvolvimento. Esta uma afirmação impregnada de ideologia desenvolvimentista opondo a cidade, moderna, e o campo, atrasado. Essa dicotomia nunca contribui para o entendimento qualificado do espaço brasileiro.

O documento conclui sobre a realidade regional fazendo as seguintes sínteses:

a) Nas macrorregiões existe uma coexistência de sub-regiões dinâmicas e sub regiões com precárias condições;

b) Presença de dinâmicas microrregionais com um perfil territorial disperso, com baixo crescimento econômico e expansão natural da população;

c) Persistência de um padrão macrorregional de desigualdade entre Norte/Nordeste e Sul/Sudeste e o Centro Oeste se aproximando do último bloco;

d) Uma distância profunda entre os rendimentos e outras variáveis apresentadas pela Amazônia e o Semi-Árido nordestino.

Levando em consideração as quatro sínteses acima, o mesmo documento chega à conclusão que é preciso "[...] atuar em diversas escalas, com destaque para os níveis sub- 


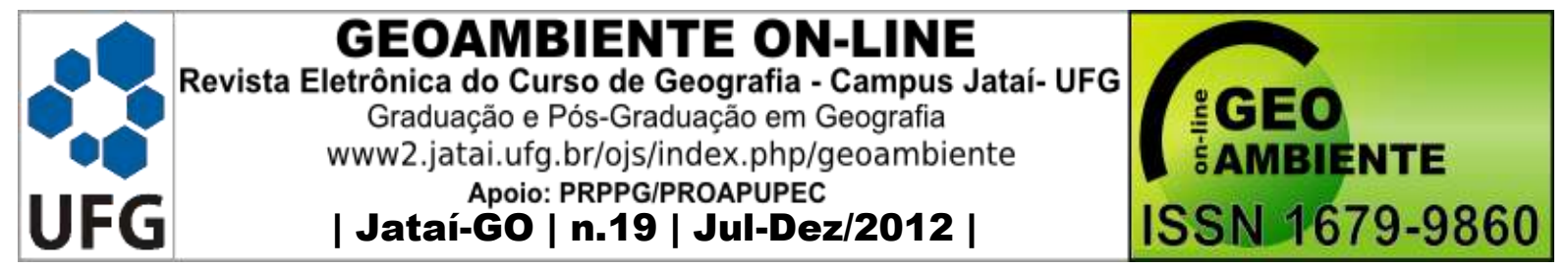

regionais, que tanto revelam contrastes extremos como oferecem trajetórias de desenvolvimento bastante distintas." (BRASIL, 2009:15).

A abordagem multi-escalar é salutar, porém o documento não apresenta as instâncias e nem órgãos que irão operacionalizar a intervenção nesses diversos níveis. $\mathrm{O}$ documento apresenta apenas Planos e Programas que seriam responsáveis por essa implementação, como o PAS - Plano Amazônia Sustentável, o PDNE - Plano Estratégico de Desenvolvimento Sustentável do Nordeste e o Plano Estratégico de Desenvolvimento do Centro Oeste - PDCO. O Programa de Gestão da Política de Desenvolvimento Regional e Ordenamento Territorial seria o elemento mais próximo para gerir, entretanto, o documento ainda não deixa claro como será esta organização.

Em relação aos objetivos da Política Nacional de Desenvolvimento Regional, o documento aponta como um importante objetivo fazer um contra-balanço a lógica centrípeta das forças de mercado, por meio da promoção e valorização da diversidade regional, conciliando assim competitividade e expressão produtiva de valores sócio-culturais diversos. O Ministério do Interior (BRASIL, 2000) alerta para um possível risco de fragmentação da economia e, portanto, da sociedade e do território. Já que esta visão esta presa à visão das Macrorregiões.

\footnotetext{
Nossa interpretação é de que o processo em pauta está promovendo a dissolução das regiões tradicionais e criando outras novas. Estudos têm mostrado a importância da proximidade na formação de novas estruturas produtivas, seja pela maior facilidade de gestão ao nível local através de cooperações informais com atores locais como firmas, universidades, coletividades, ou seja, através de identidades e status econômico dos consensos regionais [...] (BRASIL, 2000:20).
}

A PNRD é uma política nacional porque só através do nacional que se pode estabelecer uma coerência e efetividade aos esforços de desenvolvimento regional. A PNRD é uma política do governo federal através da articulação de vários ministérios como os que atuam na infra-estrutura pública, na organização de bases territoriais, pelos responsáveis pelas políticas de desenvolvimento setorial ou regulação econômica ou pelas políticas de forte impacto social. A PNDR é uma abordagem das desigualdades regionais em múltiplas escalas e se orienta através de políticas e programas que promovam o desenvolvimento territorial.

O documento da PNRD aponta, portanto, que uma das escalas de atuação é nacional. A esta escala caberia a definição de critérios gerais de atuação, identificando as sub-regiões 


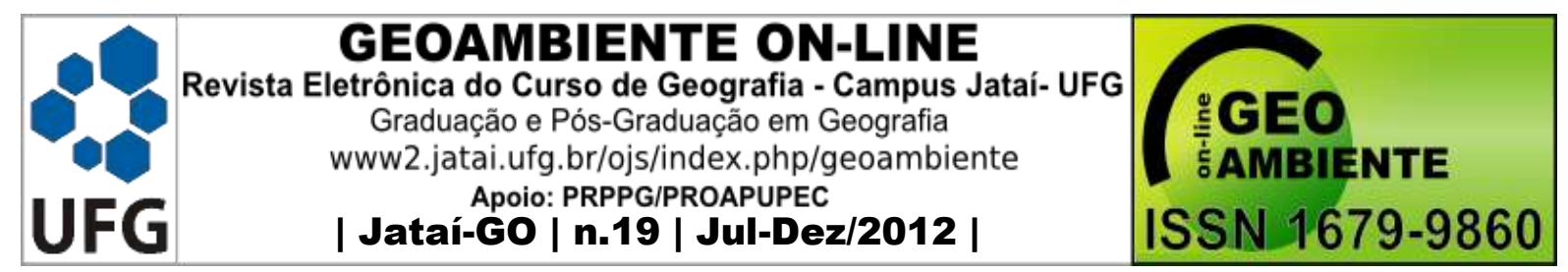

prioritárias e os espaços preferenciais de intervenção, com os seguintes responsáveis: Câmara de Políticas de Integração Nacional e o Comitê de Articulação Federativa sob a coordenação da Casa Civil da Presidência da República.

Outra escala de atuação é a Macrorregional que tem como encargo a elaboração de planos estratégicos de desenvolvimento, a articulação de diretrizes e ações de desenvolvimento e promoção de iniciativas em territórios priorizados. Os órgãos responsáveis pela operacionalização das políticas seriam a SUDAM, SUDENE e SUDECO.

Nas instâncias sub-regionais residiria o foco operacional da política. Destacam-se duas áreas prioritárias: o semi-árido nordestino e a faixa de fronteira. O semi-árido pela sua notória concentração de pobreza extrema e fragilidade econômica e a faixa de fronteira pela sua importância estratégica no objetivo maior da integração sul-americana. A unidade de articulação das ações federais nas sub-regiões atenderá pelo nome de Mesorregiões diferenciadas.

No que se refere à implementação da política, o documento elenca como áreas prioritárias as seguintes mesorregiões: Alto Solimões, Vale do Rio Acre, Bico do Papagaio, Chapada das Mangabeiras, Xingó, Chapada do Araripe, Águas Emendadas, Vale do Jequitinhonha e do Mucuri, Bacia do Rio Itabapoana, Vale do Ribeira, Grande Fronteira do Mercosul e Metade Sul do Rio Grande do Sul.

Define ainda um programa promoção econômica das sub-regiões, o PROMOVER que trabalha com as comunidades no sentido de identificar e apoiar vocações econômicas locais por meio da estruturação de arranjos produtivos e cadeias produtivas, numa óticas que conciliaria promoção da competitividade e inclusão social.

\section{Algumas conclusões sobre a política regional}

- A regionalização é atividade relacionada com o exercício de poder. O Estado é o elemento central na regionalização institucionalizada. Os movimentos sociais também constroem sistemas de regionalização para reagir e apresentar suas demandas para o Estado. Nesse jogo relacional de poder, a geografia estuda através dos contextos históricos específicos, as características epistemológicas que este conceito assume ao longo de sua trajetória e contornos que as políticas regionais desenvolvem. 


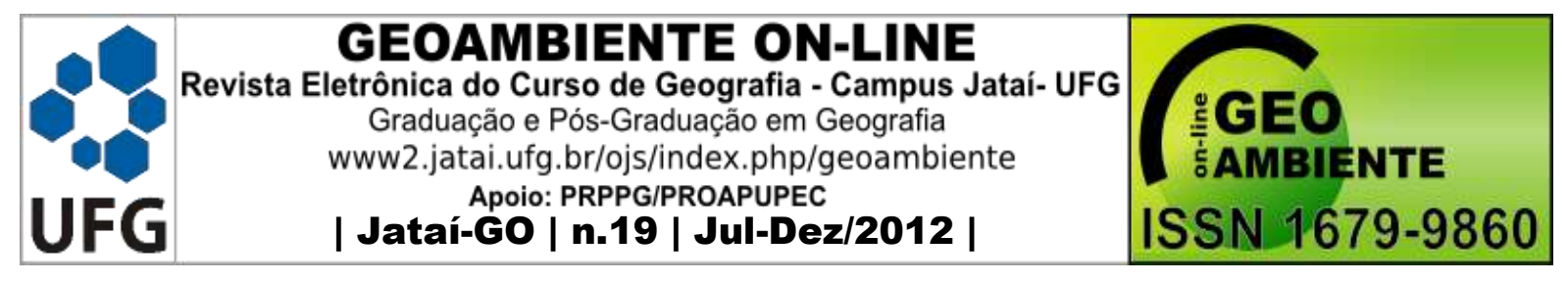

- A região e a regionalização durante o paradigma do Determinismo Ambiental se desenvolvem com base nas teorias evolucionistas e o processo de regionalização vai estar relacionado à equação população - recurso. No Possibilismo, a região seria uma entidade auto-evidente. Duas categorias são fundamentais para compreender a formação da região - modo de vida e a circulação. Na regionalização do Possibilismo, o homem desponta como um ator importante, pois a natureza oferecia um conjunto de possibilidades para esse mesmo homem que, através de sua cultura, imprimiria marcas na paisagem.

- Na Nova Geografia se estabelece a noção de complexos espaciais ou regionais, se preocupando com a construção de uma abordagem multidimensional. O espaço geográfico se configura como complexo e sistêmico, onde qualquer variável espacializada tem um valor que só pode ser mensurado quando relacionado com os espaços vizinhos. Desenvolvem-se as noções de região polarizada, região funcional e regiões homogêneas. A abordagem sistêmica se enquadra no arsenal metodológico deste paradigma. E é nesta ferramenta metodológica que a Política Nacional de Desenvolvimento Regional do Governo Lula irá alicerçar.

- As críticas elencadas neste trabalho a metodologia de regionalização do Governo Lula são elencadas dessa forma:

a) Ao se basear na abordagem sistêmica, a política regional do governo Lula se pretende construir regiões pautadas em sistemas abertos. Na verdade, a região configurar-se-ia em um crescente modelo de fechamento da sociedade. A dita abertura do sistema e, em última instância, a abertura da própria região é no fundo falsa, porque serve apenas para captar as tensões sociais e elaborar para elas as condições necessárias para a volta ao equilíbrio anterior.

b) A PNDR não rompe com o desenvolvimentismo, pois como vimos essa é uma matriz de pensamento europeu que apresenta sérios problemas ao ser aplicado na América Latina e, fundamentalmente, no Brasil;

c) A metodologia da PNRD rompe com a lógica das macrorregiões que foram o objeto das políticas de desenvolvimento regional nas décadas de 1960 e 1970. Porém, quando a PNRD propõe a revitalização de instituições como SUDAM, SUDENE e SUDECO o Governo formula uma metodologia nova de análise regional e sob formas velhas de 


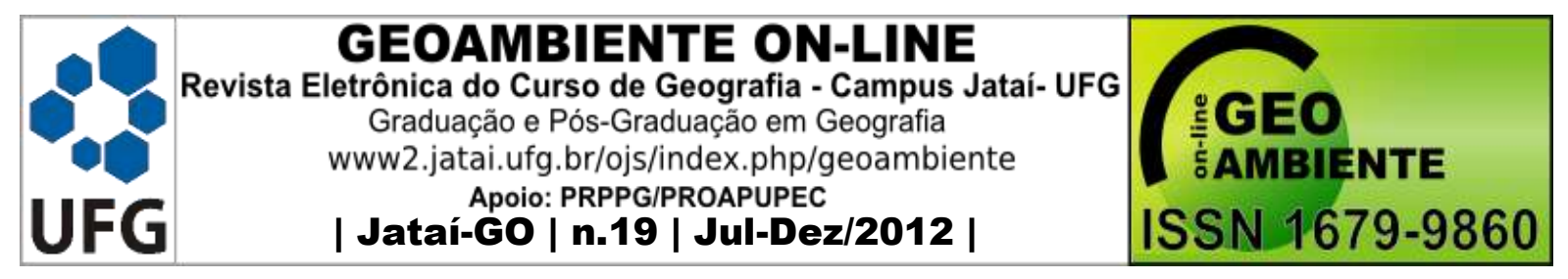

operacionalizar essa política. O resultado é uma política é, no seu cerne, contrasensual.

d) A PNDR aponta polaridades expressa no binômio litoral-interior e outra no sentido Norte-Sul. No que se refere ao litoral-interior, as desigualdades se expressam na densidade populacional, enquanto que, na relação norte-sul, são os indicadores como nível de escolaridade, grau de urbanização e rendimento médio domiciliar que compõem a diferenciação. Ao apontar essas polaridades, o documento deixa nas entrelinhas que é preciso fazer uma distribuição equânime da população pelo território nacional. Isto é um erro, já que nós temos biomas sensíveis a um grau elevado de antropização como o Pantanal e a Amazônia.

e) A abordagem multi-escalar é salutar, porém o documento não apresenta as instâncias e nem órgãos que irão operacionalizar a intervenção nesses diversos níveis. $O$ documento apresenta apenas, Plano e Programas.

\section{Referências Bibliográficas}

BEZZI, Meri Lourdes. Região: uma (re) visão historiográfica - da gênese aos novos paradigmas. Santa Maria: Ed. da UFSM, 2004.

BRASIL. MINISTÉRIO DA INTEGRAÇÃO NACIONAL. Reflexões sobre políticas de integração nacional e de desenvolvimento regional. Brasília, 2000.

BRASIL. MINISTÉRIO DA INTEGRAÇÃO NACIONAL. Política Nacional de Desenvolvimento Regional (PNRD). Disponível em: http://www.integracao.gov.br/. Acesso em: 01 junho 2011.

BRASIL. MINISTÉRIO DA INTEGRAÇÃO NACIONAL. Política Nacional de Desenvolvimento Regional (PNRD): sumário executivo. Disponível em: http://www.integracao.gov.br/. Acesso em: 01 junho 2011.

BRASIL. MINISTÉRIO DA INTEGRAÇÃO NACIONAL. Política Nacional de Desenvolvimento Regional (PNRD): proposta para discussão. Brasília, 2003. Disponível em: http://www.integracao.gov.br/. Acesso em: 01 junho 2011.

CORRÊA, Roberto Lobato. Região e Organização Espacial. São Paulo: Ática, 1995.

DEMO, Pedro. Metodologia Científica em Ciências Sociais. São Paulo: Atlas, 1981. 


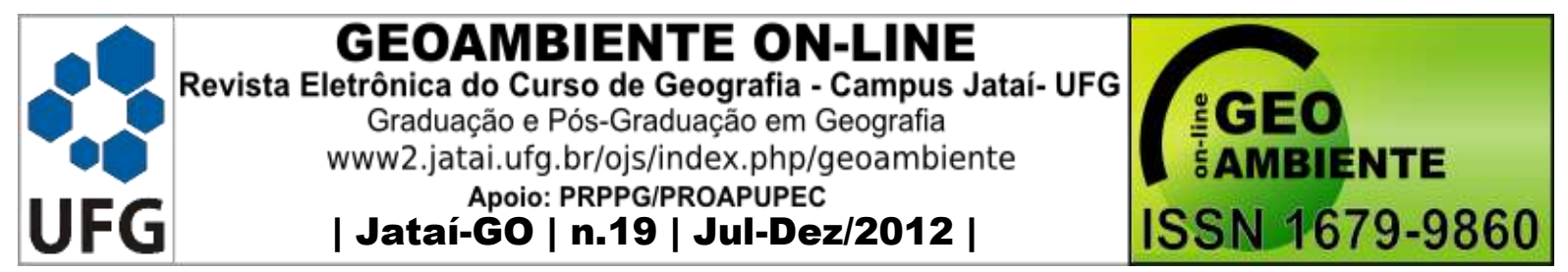

GÓMEZ, Jorge Ramon Montenegro. Desenvolvimento em (des) construção: provocações e questões sobre desenvolvimento e geografia. IN: FERNANDES, B.M.;MARQUES, M.I.M.;SUZUKI, J.C.(Orgs.) Geografia Agrária - teoria e poder. São Paulo: Expressão Popular. 39-54 p. 2007.

HAESBAERT, Rogério. A (des) ordem mundial, os novos blocos de poder e o sentido da crise. IN: Geografia, território e tecnologia. Revista Terra Livre - AGB. São Paulo: Marco Zero, n 09, julho-dezembro. 103-128 p. 1991.

LÉVI-STRAUSS, Claude. A noção de estrutura em Etnologia. São Paulo: tempo brasileiro, 15/16, pp. 67-68.

MORAES, Antônio Carlos Robert. Geografia - pequena histórica crítica. São Paulo: Hucitec, 2008.

RIST, Gilbert. El desarrollo: historia de una creencia occidental. Madri: Los Libros de La Catata, 2002. 